\title{
Recovery and Recrystallization of Ferrite in Warm Forging of a Medium Carbon Steel
}

P. Zhao and J.D. Boyd

Dept. of Mech. Eng., Queen’s University, Kingston, ON K7L 3N6, Canada

Warm forging produces high dimensional accuracy and enhanced mechanical properties [1-3]. When forging is carried out at temperatures below $\mathrm{Ar}_{1}$, the transformed ferrite + pearlite is deformed, and the ferrite can be refined by recovery and recrystallization. The current research investigates microstructural evolution in a $\mathrm{Nb}$-microalloyed medium- $\mathrm{C}$ steel, during warm forging. 35-mm diam. bars were forged to 12-mm thick plates, following the schedule given in Fig. 1. Samples were quenched immediately following the first 2 deformations (' 1 ' and ' 2 '), and the final plate was air cooled ('3').

Sample 1 exhibits the elongated austenite grain structure produced by the first deformation $\left(800^{\circ} \mathrm{C}\right)$. Sample 2 shows some transformed ferrite and pearlite. Grain boundary ferrite and a small amount of intragranular ferrite comprise $21 \%$ of the microstructure. The deformed ferrite recovers quickly and forms subgrains having a mean linear intercept of $0.46 \pm 0.14 \mu \mathrm{m}$ (Fig. 2). Some recrystallized ferrite grains are also observed in sample 2 (Fig. 3). The dimensions of these recrystallized grains are comparable to the subgrains in the recovered ferrite.

In sample 3 , deformation at $650^{\circ} \mathrm{C}$ (below $\mathrm{Ar}_{1}$ ) followed by air cooling produces elongated grain boundary ferrite and pearlite (Fig. 4). The mean dimensions of the elongated ferrite grains are length $=3.62 \pm 2.01 \mu \mathrm{m}$ and width $=1.33 \pm 0.75 \mu \mathrm{m}$. Fig. 5 shows a typical area of recovered elongated grain boundary ferrite grains. The substructure comprises $0.73 \pm 0.09 \mu \mathrm{m}$ subgrains. It was confirmed by electron diffraction that the individual subgrains have small $\left(<10^{\circ}\right)$ misorientations with respect to each other. Some areas of recrystallized ferrite are also observed in Sample 3 (Fig. 6). The mean linear intercept diameter of the recrystallized ferrite grains is $0.66 \pm 0.27 \mu \mathrm{m}$, again comparable to the subgrain size.

It is concluded that warm forging can produce significant microstructural refinement through the mechanisms of ferrite recovery and recrystallization. Sub-micron ferrite subgrains and recrystallized ferrite grains can be obtained.

References

[1] S. Sheljaskov, J. Mater. Processing Technol. 46 (1994) 3.

[2] J. H. Reynolds et al, Mater. Sci. Technol. 4 (1988) 586.

[3] C. García-Mateo et al, Iron \& Steelmaker. 27 (2000) 79. 

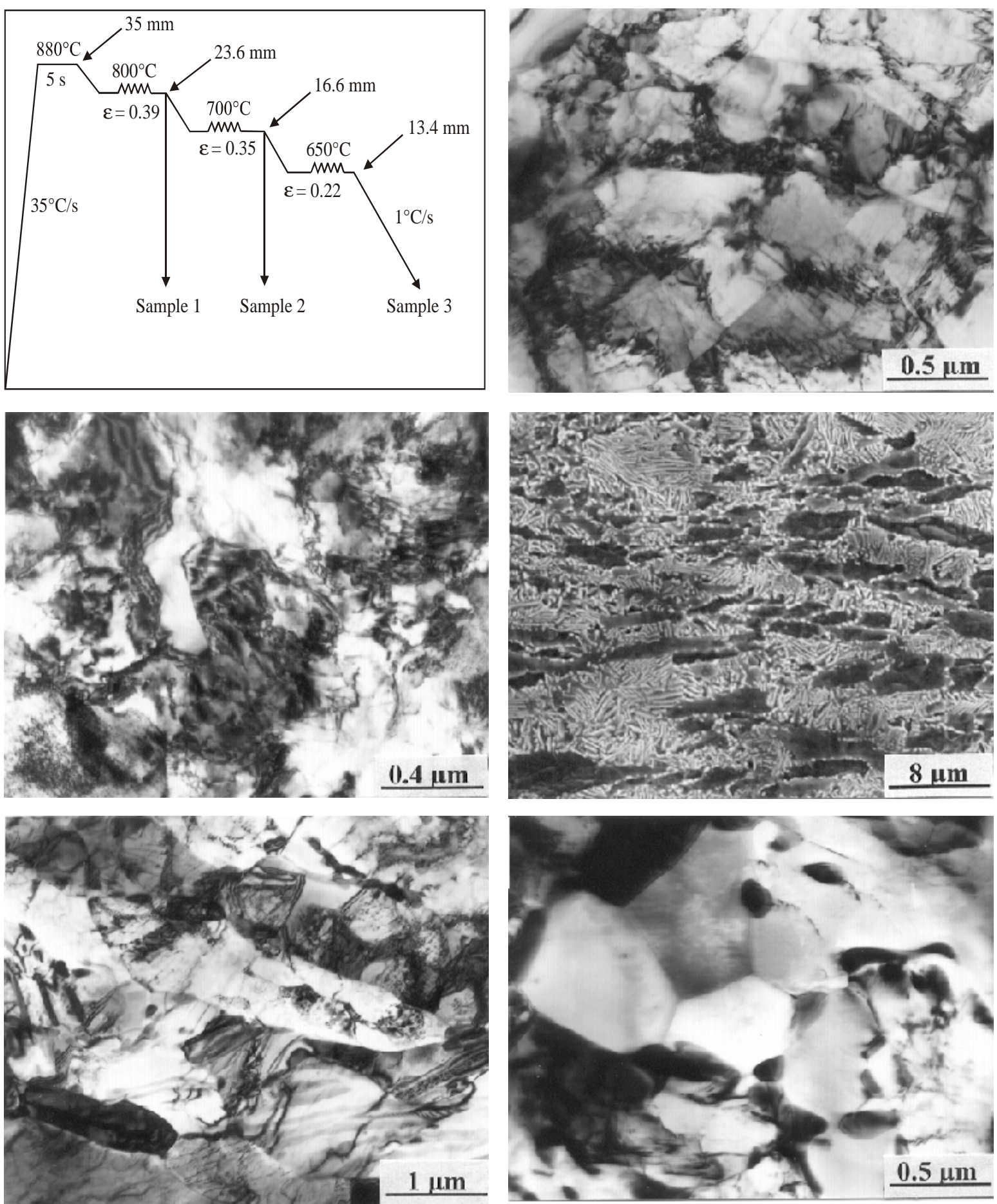

Figure 1 Experimental warm forging schedule.

Figure 2 Typical TEM microstructure of quenched sample 2. Figure 3 Quenched sample 2, showing a recrystallized grain. Figure 4 Typical SEM microstructure of air-cooled sample 3. Figure 5 Typical TEM microstructure of air- cooled sample 3. Figure 6 Air-cooled sample 3, showing a recrystallized area.

\begin{tabular}{|c|c|}
\hline Fig. 1 & Fig. 2 \\
\hline Fig. 3 & Fig. 4 \\
\hline Fig. 5 & Fig. 6 \\
\hline
\end{tabular}

